\title{
A critical discussion of the electromagnetic radiation (EMR) method to determine stress orientations within the crust
}

\author{
M. Krumbholz ${ }^{1,2}$, M. Bock ${ }^{3}$, S. Burchardt ${ }^{1,2}$, U. Kelka ${ }^{3}$, and A. Vollbrecht ${ }^{1}$ \\ ${ }^{1}$ Geoscience Center, Georg-August-University of Göttingen, Göttingen, Germany \\ ${ }^{2}$ Solid Earth Geology, Department of Earth Science, Uppsala University, Uppsala, Sweden \\ ${ }^{3}$ Institute of Geosciences, Johannes-Gutenberg-University of Mainz, Mainz, Germany \\ Correspondence to: M. Krumbholz (michael.krumbholz@geo.uu.se)
}

Received: 28 June 2012 - Published in Solid Earth Discuss.: 24 July 2012

Revised: 11 October 2012 - Accepted: 17 October 2012 - Published: 26 November 2012

\begin{abstract}
In recent years, the electromagnetic radiation (EMR) method has been used to detect faults and to determine main horizontal stress directions from variations in intensities and directional properties of electromagnetic emissions, which are assumed to be generated during microcracking. Based on a large data set taken from an area of about $250000 \mathrm{~km}^{2}$ in Northern Germany, Denmark, and southern Sweden with repeated measurements at one location during a time span of about $1.5 \mathrm{yr}$, the method was systematically tested. Reproducible observations of temporary changes in the signal patterns, as well as a strongly concentric spatial pattern of the main directions of the magnetic component of the EMR point to very low frequency (VLF) transmitters as the main source and hence raise serious concerns about the applicability of the method to determine recent crustal stresses. We conclude that the EMR method, at its current stage of development, does not allow determination of the main horizontal stress directions.
\end{abstract}

\section{Introduction}

Phenomena like earthquake lights (Derr, 1986), the disturbances of radio communication prior to and during earthquakes (e.g. King, 1983; Nagamato et al., 2008), and increased intensities of electromagnetic radiation above faults (e.g. Nikiforova et al., 1989; Mallik et al., 2008) are currently accepted and are thought to be associated with natural sources of electromagnetic radiation (EMR). However, the generation mechanisms of this natural EMR are still controversially discussed by various authors and may be manifold. Some of the discussed sources are, for example, electrokinetic effects (e.g. Gershenzon and Gokhberg, 1993; Clint, 1999), triboelectrification and contact electrification (e.g. Parkhomenko, 1971), and piezoelectricity (e.g. Nitsan, 1977; Gomshei and Templeton, 1989). However, at laboratory scale, the generation of EMR was observed during deformation experiments on different materials, such as ice (Fifolt et al., 1993; Petrenko, 1993), metals (Misra and Kumar, 2004), amorphous materials like glass ceramics (Bahat et al., 2002), and different rock types (Yamada et al., 1989; Enomoto and Hashimoto, 1992; Koktavy et al., 2004; Mori and Obata, 2008), mostly independent of their water saturation (Yoshida and Ogawa, 2004). These observations strongly restrict possible source mechanisms. Furthermore, it was observed that the EMR pulses measured during these experiments correlate with acoustic emissions related to microcracking events (Yamada et al., 1989; Koktavy et al., 2004; Rabinovitch et al., 2007; Mori and Obata, 2008). Therefore, different models have been recently discussed that relate the generation of natural EMR to the growth of micro-cracks (e.g. Misra, 1975; Yamada et al., 1989; Rabinovitch et al., 2007).

Laboratory experiments by Koktavy et al. (2004) and Misra and Kumar (2004) show that crack-related EMR exhibits directional properties with the strongest intensities parallel to the orientation of the crack walls. Consequently, a crack-related model has to be able to explain the generation of electric potentials (dipoles) perpendicular to the crack walls (Fig. 1), so that the magnetic component of the electromagnetic field generated by these electric potentials propagates parallel to the micro-crack walls. In detail, 


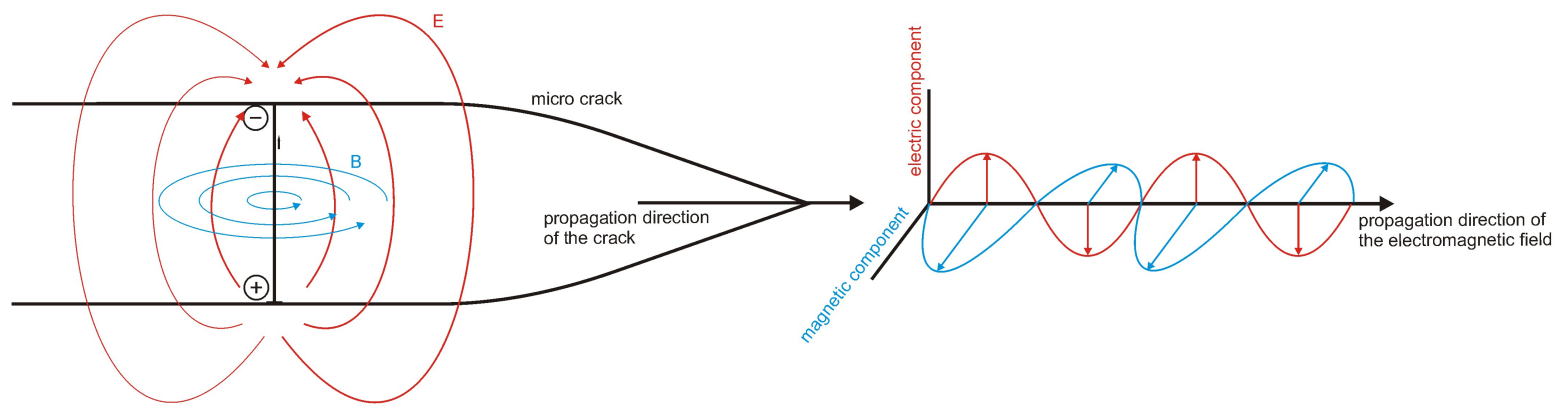

Fig. 1. Principal model of the polarisation of a micro-crack associated with electromagnetic emissions. During the formation and/or growth of a micro-crack, oscillating dipoles are generated that are orientated perpendicular to the micro-crack walls (Rabinovitch et al., 2007). Therefore, the measured magnetic component $(\mathrm{B}$, blue) of the resulting electromagnetic field propagates parallel to the orientation of the micro-crack.

for the generation of electric potentials along crack walls, different processes have been considered: the emission of charged particles out of the crack walls during crack propagation (e.g. Brady and Rowell, 1986; Enomoto and Hashimoto, 1990), the movement of dislocations induced by changes in the stress field around the growing crack (e.g. Misra and Gosh, 1980; Slifkin, 1993), contact electrification and triboelectrification (Parkhomenko, 1971), or electrical potentials that arise from opening cracks in materials exposed to physical gradients, such as temperature (Petrenko, 1993; O'Keefe and Thiel, 1995). These models, however, are not fully material independent, cannot explain directed emissions, or are not capable of explaining the observed frequencies and pulse shapes. For a detailed discussion of the most likely EMR-emitting processes, the reader is referred to Gershenzon and Bambakidis (2001), Frid et al. (2003), and Rabinovitch et al. (2007).

The so far most reliable model that explains crack-induced EMR and is independent of material properties is based on surface vibrational waves (Rabinovitch et al., 2007). According to this model, EMR is generated by the oscillation of charge carriers around their steady-state positions after the breakage of atomic bonds. This involves the collective oscillation of atoms in lines, where positive and negative charges move in diametrically opposite phases forming dipoles. Their oscillation amplitudes exponentially decrease with increasing distance to the crack walls. Consequently, the vibrations of the charge carriers create surface waves (Rayleigh waves) on both sides of the crack. When time-averaged, the crack surface is electrically neutral because of an asymmetric breaking mechanism, which is characteristic of surface vibrational optical waves. The generated dipoles oscillate perpendicular to the crack orientation and, thus, produce a polarised electromagnetic field that includes a magnetic component parallel to the crack surface.

Based on the assumption that most tectonic micro-cracks that formed close to the surface are extensional (Mode I) cracks and propagate normal to the minimum principal compressive stress $\sigma_{3}$ (i.e. parallel to the $\sigma_{1} / \sigma_{2}$ plane)
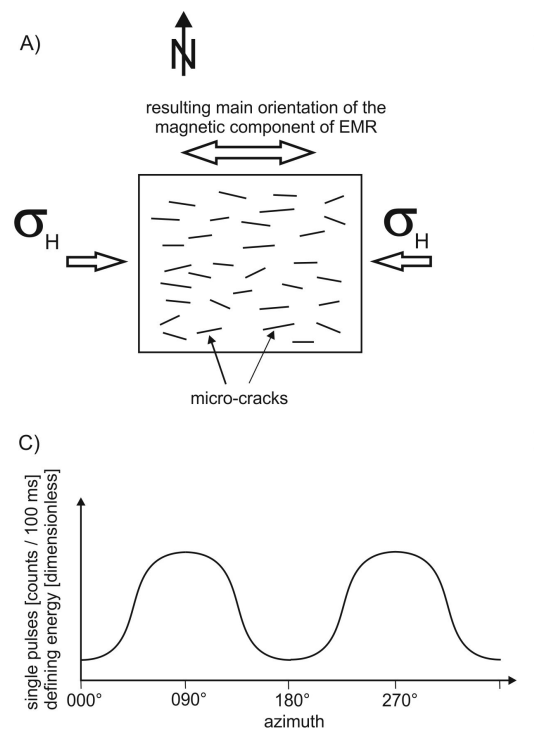

B)

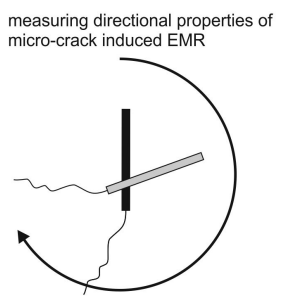

D) single pulses [counts / $100 \mathrm{~ms}$ ] single pulses [counts $/ 100 \mathrm{~ms}$ ]
defining energy [dimensionless]

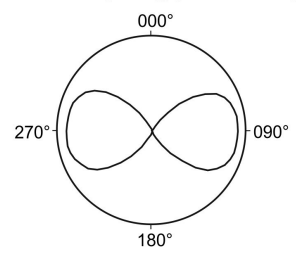

Fig. 2. EMR measuring setup. (A) The main orientation of the magnetic component of EMR is expected to be parallel to the associated micro-cracks (Obermeyer, 2005b). (B) The directional EMR properties are determined by measuring its magnetic component with the ferrite-core antenna. (C, D) Sketch of determined EMR intensities that results from measurements of its magnetic component as a function of direction. In this example the maximum values are measured in $\mathrm{E}-\mathrm{W}$ direction.

(e.g. Kranz, 1983; Vollbrecht et al., 1989; Zang et al., 1996; Vollbrecht et al., 1999), the main direction of the measured (crack-induced) magnetic component of EMR should correlate with the maximum horizontal normal stress direction $\left(\sigma_{H}\right.$, i.e. the intersection line of the $\sigma_{1} / \sigma_{2}$ plane with the surface; Fig. 2). Based on this concept, the measurement of the directional properties of crack-induced EMR in the field would offer a low-effort tool to determine the main horizontal stress direction.

First field studies have been carried out with the so-called Cerescope, a portable measuring device (Obermeyer, 2005a, 
b; details see below), considering different geological environments (e.g. Reuther et al., 2002; Lauterbach, 2005; Lichtenberger 2005, 2006a,b; Mallik et al., 2008; Reuther and Moser, 2009; Greiling and Obermeyer, 2010a). Even though some of these studies seem to have produced promising results, up to now the EMR method has not been fully accepted and has only been used by a small number of research groups. For this reason we carried out an extensive and systematic study based on measurements over long time intervals and large areas to evaluate the applicability of the Cerescope to determine the direction of $\sigma_{H}$ by measurements of the magnetic component ( $\left.B_{\mathrm{EMR}}\right)$ of EMR signals.

\section{Method}

The Cerescope is sold by GE\&O GmbH, Karlsruhe (Germany). It measures the magnetic component of the EMR in the range of 5 to $50 \mathrm{kHz}$. This frequency range defines the depth resolution of the measurements, because the skin depth (penetration depth) of EMR is a function of its frequency and the electric material properties, and increases with decreasing frequency. The skin depth itself is defined as the depth at which the original amplitude of a signal is reduced to $1 / \mathrm{e}(37 \%)$. Therefore, lower frequencies allow evaluation of a larger rock volume and hence improve the statistics. Realistic values for the skin depth of geological materials in the used frequency range lie in the range from hundreds to thousands of meters for crystalline rocks (e.g. Takahara et al., 2010) and from tens to hundreds of meters for sedimentary rocks (e.g. Reuther and Moser, 2009).

The Cerescope is equipped with a ferrite-core antenna, which has its maximum sensitivity for the magnetic component of the electromagnetic field at a frequency of $12.8 \mathrm{kHz}$ (Greiling and Obermeyer, 2010a). Some previous studies, which outline technical data of the Cerescope hardware in more detail, describe the antenna as most sensitive when its long axis is parallel to the propagation direction of the electromagnetic waves (Lichtenberger, 2005, 2006a; Reuther and Moser, 2009) or perpendicular to the propagation direction of the waves (Greiling and Obermeyer, 2010a).

The Cerescope is additionally equipped with a filter that "rejects most intransient noise automatically" (Obermeyer, 2005a; see also Lichtenberger, 2006a,b; Greiling and Obermeyer, 2010a). Frequency bands that appear to be less disturbed can be selected, or seemingly disturbed frequency bands can be excluded, respectively, using low-, high-, bandpass or notch filters. However, only the following filter settings are available: (1) a band-pass filter only, (2) two notch filters, (3) a low-pass plus one notch filter, and (4) a highpass plus one notch filter (Obermeyer, 2005b). Furthermore, the signal/noise ratio is improved automatically by the pulseaveraging technique which is part of the Cerescope software (Greiling and Obermeyer, 2010a). Based on the fact that natural crack-related EMR signals should occur as transient sig- nals in fast succession (bursts), the measuring device "is also able to detect bursts automatically" (Obermeyer 2005a). For this, a special burst-detecting algorithm analyses the shapes of the incoming signals.

Apart from the adjustment of the frequency filters, the amplification (between 90 and $120 \mathrm{~dB}$ ) and a discrimination level have to be selected by the operator. Only signals exceeding the selected discrimination level are taken into account by the device. A single measurement including calculation and storage of the results lasts up to about 1 to $3 \mathrm{~s}$, while the measurement itself takes only $100 \mathrm{~ms}$ (Obermeyer, 2005a; Greiling and Obermeyer, 2010a).

The measuring parameters that are stored by the Cerescope are: (1) the number of transient single pulses [counts/100 ms], (2) the number of bursts or pulse packages (pulses that occur in fast succession and cannot be discriminated by the Cerescope) [counts $/ 100 \mathrm{~ms}$ ], (3) the medium amplitude of the pulse packages [dimensionless], (4) the defining energy of the pulse packages [dimensionless], and (5) the average frequency of the pulse packages [kHz]. The raw data are not accessible. The parameters that are typically evaluated in former studies and also in the present study are the number of transient single pulses (1) and the defining energy of the pulse packages (4).

Based on the receiving pattern of the antenna, three measurement methods exist: (1) The line measurement that is used to detect active faults and is, according to the distributor (Obermeyer, 2005b), based on the occurrence "of loci of high stresses" within fault cores that are related to an increased number of micro-cracking events. During line measurements, the Cerescope runs in a time-triggered mode, and the antenna is held vertically, while moving along a profile. Above active faults, the measured EMR intensities should increase. By combining data of several profiles across the same fault, the strike of the faults can be mapped, while asymmetries in the geometry of the intensity pattern above the fault can be used to draw conclusions about the dip direction of the fault plane. (2) Horizontal measurements are used to determine the main horizontal stress direction (Obermeyer, 2005b; Greiling and Obermeyer, 2010a). During horizontal measurements, the antenna is horizontally rotated around a vertical axis to determine the main direction of the magnetic component of the EMR that is, according to, for example, Obermeyer (2005b), supposed to coincide with the preferred micro-crack orientation and should thus reflect the main horizontal stress direction $\left(\sigma_{H}\right)$ (Fig. 2). During this study, all horizontal measurements were taken with $5^{\circ}$ increments over $360^{\circ}$ so that a complete horizontal measurement consists of 72 individual measurements to warrant high accuracy, reproducibility, and comparability. (3) Vertical measurements are comparable to horizontal measurements, with the difference that the antenna is moved in a vertical circle; they are thus predominantly conducted in subsurface investigations. This method was also used in combination with 


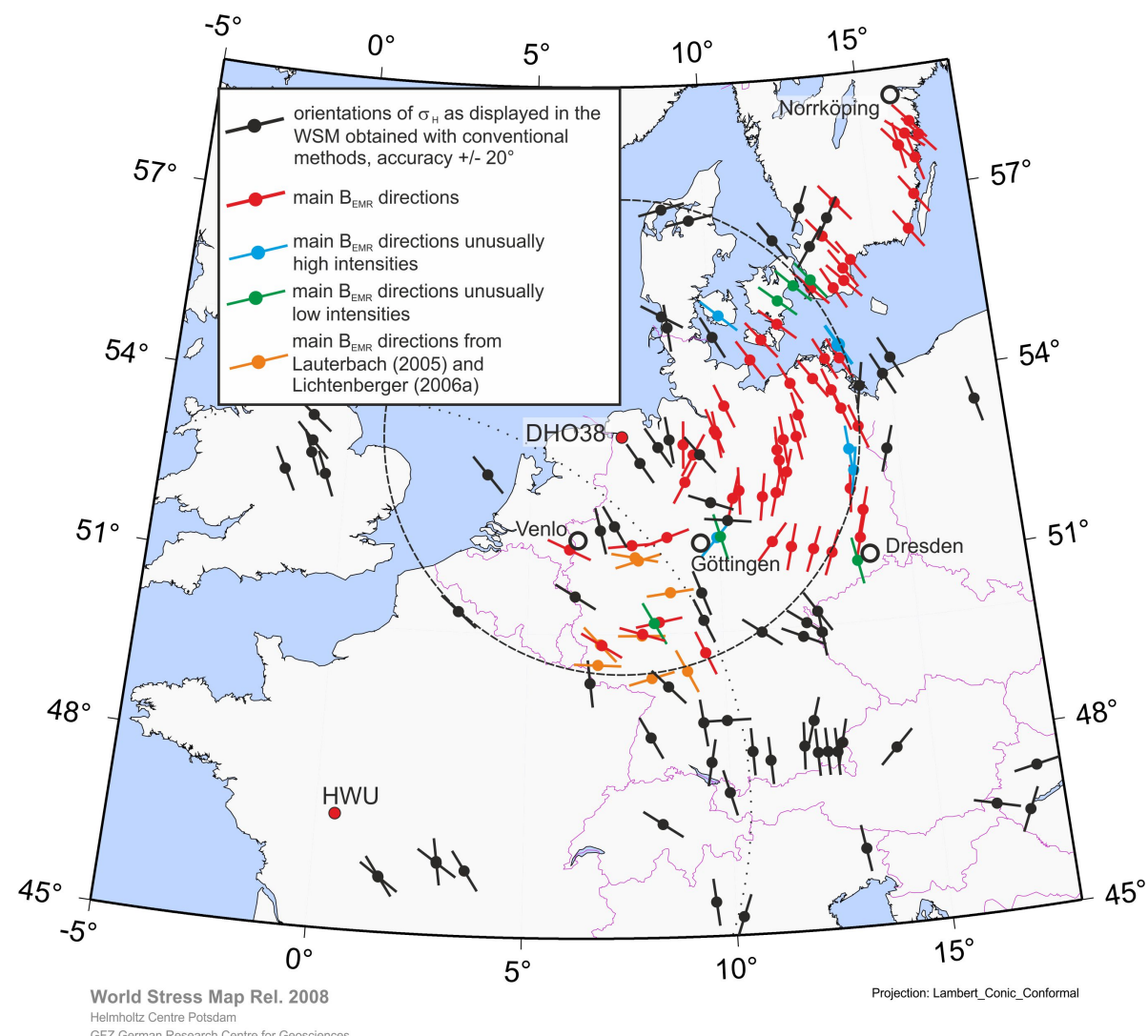

Fig. 3. Distribution of the main directions of the magnetic component of EMR ( $B_{\mathrm{EMR}}$ ) of this study in comparison with $\sigma_{H}$ as published in the WSM (Heidbach et al., 2008). Red trajectories display the measured $B_{\text {EMR }}$ main directions with typical intensities. Blue trajectories indicate remarkably high intensities and green trajectories remarkably low intensities. Grey and black trajectories show $\sigma_{H}$ directions as displayed in the WSM. Orange trajectories show representative results of Lauterbach (2005) and Lichtenberger (2006a).

the Kirsch equations to calculate stress magnitudes of the regional stress field (Lichtenberger, 2005, 2006a, b).

In our study, we determined the main directions of the magnetic component of the EMR $\left(B_{\mathrm{EMR}}\right)$ over a large area (see Fig. 3 in Sect. 3.1) using horizontal measurements. Additionally, we monitored the main direction of the magnetic field at one location over a long time period, between November 2008 and June 2009, with approximately weekly intervals (Sect. 3.2). The $\mathrm{N}-\mathrm{S}$ extent of the investigated area (Fig. 3) is about $900 \mathrm{~km}$ and reaches from near Frankfurt am Main (Germany) in the south to the vicinity of Norrköping (Sweden) in the north. The E-W extent is about $650 \mathrm{~km}$ and reaches from Venlo (Netherlands) in the west to Västervik (Sweden) and Dresden (Germany) in the east.

To maintain comparability, we kept the Cerescope settings as constant as possible, preferably at an amplification of $102 \mathrm{~dB}$, a discrimination level of 20 , and a frequency range between 30 and $35 \mathrm{kHz}$. Extensive tests in the beginning of this study, where we verified the effect of applying different filter settings (band-, high-, and low-pass filters as used in previous studies) and selecting different frequency ranges, amplifications, and discrimination levels, showed that these settings affect only the signal strength, but do not influence the determined main $B_{\mathrm{EMR}}$ direction. Furthermore, two Cerescopes of the same type were used during the study to exclude device-specific errors.

\section{Results}

\subsection{Spatial variation of the main $B_{E M R}$ direction (horizontal measurements)}

The results of the horizontal $B_{\mathrm{EMR}}$ measurements are displayed on a section of the World Stress Map (WSM; Heidbach et al., 2008) (Fig. 3). The obtained E-W directions in the south-western part, NE-SW directions in the southeastern part, and NW-SE directions in the northern part of the study area are most evident. The spatial distribution of the main $B_{\mathrm{EMR}}$ directions, which should coincide with the direction of $\sigma_{H}$, shows, however, in part significant deviations from the major stress directions measured with conventional methods. 


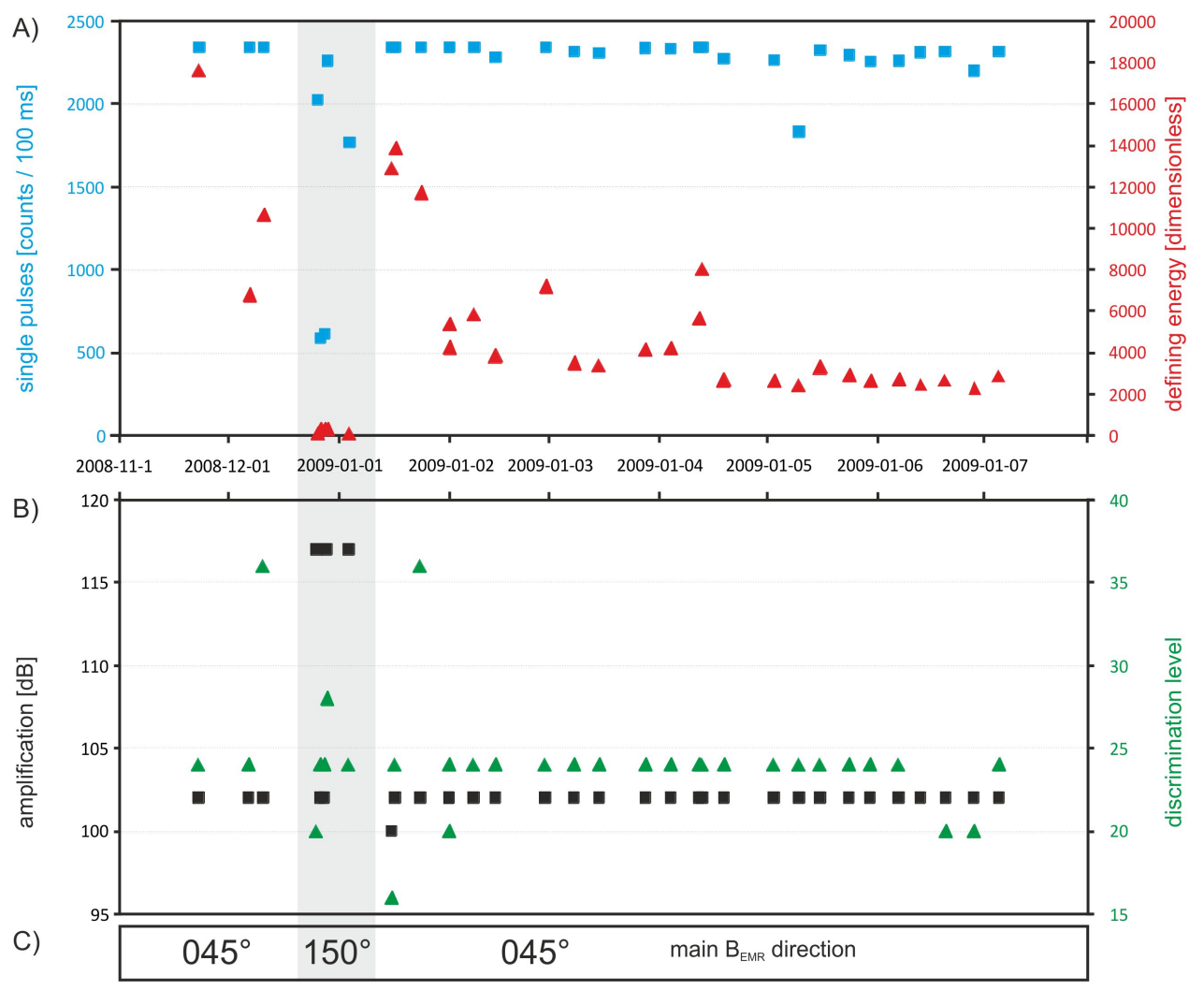

Fig. 4. Fluctuation of main $B_{\text {EMR }}$ direction over time. (A) Measurement results and (B) device settings of the Cerescope of horizontal measurements carried out near Göttingen between November 2008 and July 2009. During a two-week interval at the turn of the year, the measured main $B_{\mathrm{EMR}}$ direction (area shaded in grey) differed from the commonly observed main $B_{\mathrm{EMR}}$ direction (C). During this time, lower intensities of the single pulses and the defining energy were measured.

The main $B_{\mathrm{EMR}}$ directions in the northern part of the study area are in good agreement with directions of $\sigma_{H}$ of the WSM (Heidbach et al., 2008). In the eastern part, the main $B_{\text {EMR }}$ directions are fairly consistent with $\sigma_{H}$. In the southwestern part, however, the main $B_{\mathrm{EMR}}$ directions differ significantly from the WSM data. For the south-east, no $\sigma_{H}$ data are available from the WSM.

Considering the whole study area, the complete data set of main $B_{\mathrm{EMR}}$ trajectories displays a segment of a concentric pattern with a common centre near the town of Emden (NW Germany). Only a few measured main $B_{\mathrm{EMR}}$ directions deviate from this concentric pattern in direction and/or intensity (marked respectively green and blue in Fig. 3). However, they occurred only locally, and sometimes exhibited deviations in the main $B_{\mathrm{EMR}}$ direction as compared to adjacent measurements. Together with some representative data of Lauterbach (2005) and Lichtenberger (2006a), these directions seem to create an additional concentric pattern with a common centre near the town of Rosnay (France). Moreover, unusually low EMR intensities were commonly observed only during a short time interval (cf. Sect. 3.2).

\subsection{Temporary variation of the main $B_{E M R}$ direction}

After we observed a fluctuation of the main $B_{\text {EMR }}$ direction in time, horizontal measurements were systematically carried out over a time span of $1.5 \mathrm{yr}$ at one location near Göttingen (Germany), using two Cerescopes to exclude device-specific errors. More specifically, during the first measurement in May 2007, the main $B_{\mathrm{EMR}}$ direction was oriented $45^{\circ} \pm 10^{\circ}$. In contrast, several determinations near the end of 2007 showed a direction of $150^{\circ} \pm 10^{\circ}$, associated with significantly lower intensities.

To verify this observation, additional measurements were carried out at weekly intervals from November 2008 to June 2009 (Fig. 4). The settings (frequency range, amplification, discrimination level) of the Cerescope, as well as the time of the measurement were kept as constant as possible to keep the results comparable.

During the turn of the year from 2008 to 2009, a temporary fluctuation in $B_{\mathrm{EMR}}$ direction and intensity occurred similar to the observations made in December 2007/January 2008. The regular measurements allowed a detailed characterisation of the fluctuations; while the main $B_{\mathrm{EMR}}$ direction was rather constant during the year $\left(45^{\circ} \pm 10^{\circ}\right)$, the start and the 
end of the fluctuation sequence was characterised by a significant change of the main $B_{\mathrm{EMR}}$ direction. Furthermore, the intensities of EMR increased during the start and the end of this sequence.

During the start of the fluctuation sequence on 23 November 2008, the EMR intensities changed to unusually high values. Remarkably, the intensities of the defining energy were more strongly affected than those of the single pulses, which stayed fairly constant (Fig. 4). On 11 December 2008, the main $B_{\mathrm{EMR}}$ direction switched abruptly from $45^{\circ}$ to $150^{\circ} \pm 10^{\circ}$ and the signals exhibited very low intensities with respect to the typical values, in spite of higher amplifications. On 16 January 2009 the NE-direction was reestablished, but main $B_{\mathrm{EMR}}$ directions varied continuously between $30^{\circ}$ and $65^{\circ}$ until the end of March 2009. Afterwards, the main $B_{\mathrm{EMR}}$ direction remained again stable at $45^{\circ} \pm 10^{\circ}$.

\section{Influence of VLF transmitters}

Since the trajectories of main $B_{\mathrm{EMR}}$ directions form an arc of a circular pattern (Fig. 3), the potential influence of an artificial source has to be considered. This implies that the receiving pattern of the Cerescope antenna is probably different from what is stated by some previous studies (Lichtenberger, 2005, 2006a; Reuther and Moser, 2009). Consequently, the source of a circular pattern should be located in its centre. The NATO military transmitter "NATO VLF/MSK Marinefunkstelle Rhauderfehn" with the call sign DHO38 $\left(53^{\circ} 4^{\prime} \mathrm{N}, 7^{\circ} 36^{\prime} \mathrm{E}\right)$ is situated exactly at this location for the dominant arc. DHO38 has about 1MW power and is used for navigation and long distance communication with submarines using the very low frequency (VLF) of $23.4 \mathrm{kHz}$. The centre of the second identified arc (Fig. 3 ) coincides with the position of the French VLF transmitter HWU $\left(46^{\circ} 42^{\prime} \mathrm{N}, 1^{\circ} 14^{\prime} \mathrm{E}\right.$; frequencies 15.1, 18.3, 21.75 , $22.6 \mathrm{kHz}$ ). Even though the frequencies of DHO38 and HWU were excluded in Cerescope measurements by using a bandpass with a frequency range between 30 and $35 \mathrm{kHz}$, these transmitters are potential sources of the measured signals. In order to further substantiate this hypothesis, the above described results were re-evaluated and supplemented by further test measurements.

The maximum number of single pulses and the maximum defining energy of the pulse packages of the horizontal EMR measurements described in Sect. 3.1 (Fig. 3) and some further data from SE Sweden were plotted against the distance to DHO38 (Fig. 5). Figure 5 shows that the intensities of the defining energy are clearly a function of the distance to DHO38, with decreasing intensities with increasing distance. In contrast, the number of single pulses stays relatively constant with a maximum of 2340 counts $/ 100 \mathrm{~ms}$ within the first $300 \mathrm{~km}$ distance to DHO38, which coincides with the transmitting frequency of DHO38 of $23.4 \mathrm{kHz}$. In addition, the maximum values of single-pulse measurements follow, with regard to the selected amplification, a roughly linear function that decreases only slightly with increasing distance to DHO38.

Moreover, the daily transmission pattern of DHO38 recorded near Toulouse (France; Fig. 6; SID Monitoring Station: http://sidstation.loudet.org/home-en.xhtml) shows a typical run for the signal strength of VLF signals with lows during twilight, highs in the night and a nearly constant level during daytime. This pattern depends on the altitude of the Sun above the horizon, because the resulting height of the ionosphere, which is a reflector of VLF signals, is controlled by the Sun's irradiation. Furthermore, the transmission pattern of DHO38 shows a distinct feature, a regular daily intermission between 07:00 and 08:00 UTC. The recording time of EMR measurements with unusually low defining energy (green squares in Fig. 5) completely coincides with this daily intermission, whereas most measurements with unusually high values were measured after sunset (blue squares in Fig. 5). Positive outliers that cannot be explained by the time of the measurement were probably related to locations above faults (cf. Sect. 2 on linear measurements).

In order to further verify the influence of DHO38 (distance to measuring location $235 \mathrm{~km}$; bearing $320^{\circ}$ ), the main $B_{\text {EMR }}$ direction was measured shortly before and during its daily intermission on 15 July 2009 near Göttingen (Germany; Fig. 7). To monitor the signal strength during the start and the end of the intermission, the Cerescope was running in the time-triggered mode. The main $B_{\mathrm{EMR}}$ direction prior to the intermission was $35^{\circ} \pm 10^{\circ}$ (Fig. 7a). The most plausible explanation for the deviation of this direction and the commonly observed $45^{\circ} \pm 10^{\circ}$ may be a user specific error, such as a mistake during the orientation of the measuring setup or an (artificial) disturbance of the local magnetic field. Both could explain the consistent $10^{\circ}$ difference between these and previous measurements. However, the time relation between the shift of the measured directions and the intermission of DHO38 is obvious, so that the observed $35^{\circ} \pm 10^{\circ}$ direction can again be explained with DHO38. The main $B_{\text {EMR }}$ direction measured during the intermission of DHO38 was $175^{\circ} \pm 10^{\circ}$ (Fig. 7c) and characterised by remarkably low intensities. This direction fits poorly with the $150^{\circ} \pm 10^{\circ}$ measured during the turn of the year. However, it can be explained by RDL Krasnodar $\left(18.1 \mathrm{kHz} ; 45^{\circ} 24^{\prime} \mathrm{N}, 38^{\circ} 9^{\prime} \mathrm{E}\right.$; distance to measuring location $2160 \mathrm{~km}$; bearing $97^{\circ}$ ).

The time-triggered intensity measurements also show evidence of the strong influence of the VLF transmitter DHO38 by an abrupt decrease in intensities during its turn off (Fig. 7b) and an immediate increase with the end of the intermission (Fig. 7d). Since the usual $45^{\circ}$ main $B_{\text {EMR }}$ direction measured in Göttingen can be related to $\mathrm{DHO} 38$, it might be further argued that during the intermission of DHO38, the signal from another VLF transmitter is being measured. The latter should be located W or E of Göttingen (cf. Fig. 7c) and during the turn of the year WSW or ENE of Göttingen (cf. 

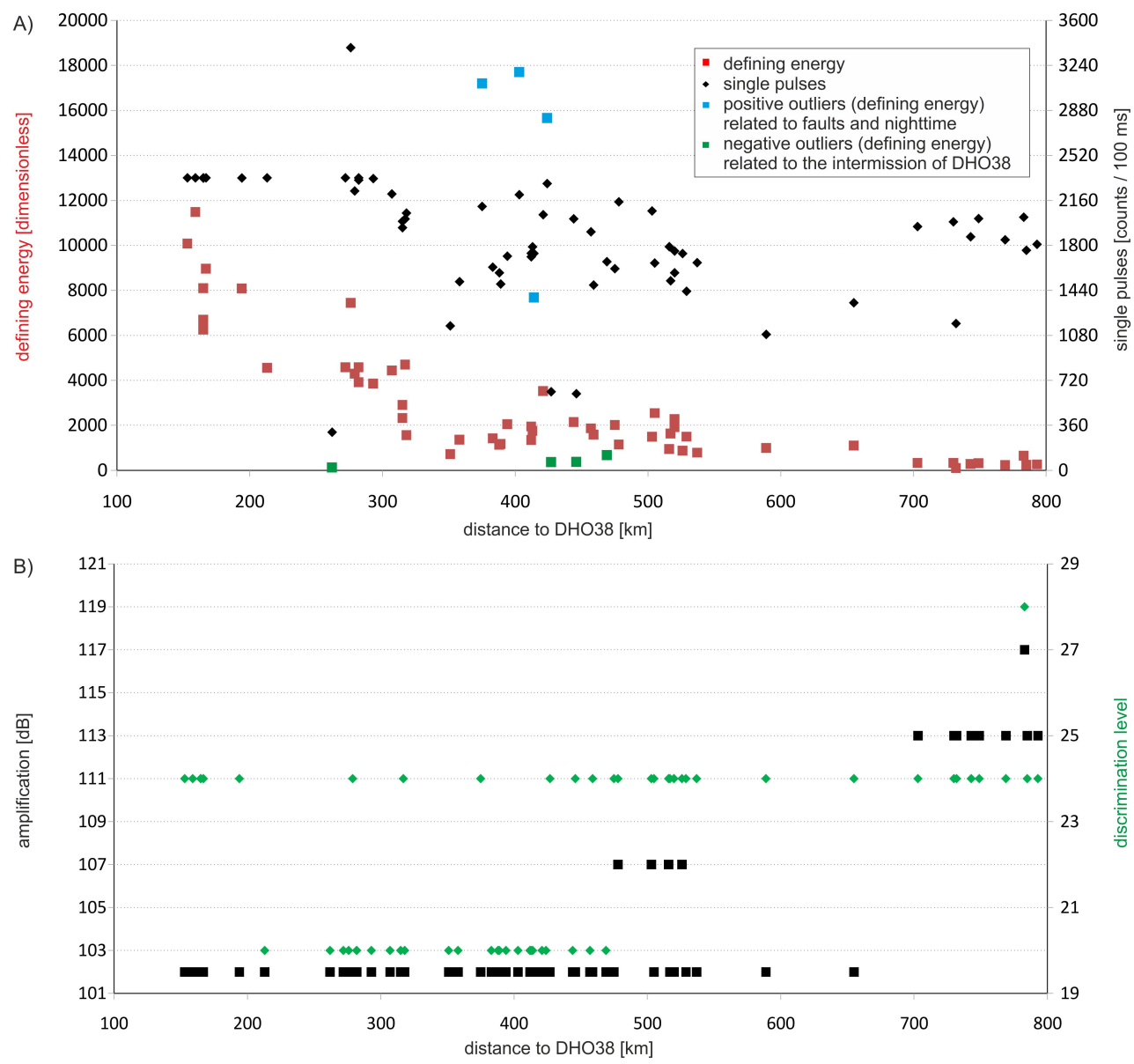

Fig. 5. (A) Maximum signal strength of horizontal measurements (cf. Fig. 3) as a function of distance to DHO38. The strength of the defining energy (red, blue, and green) is a function of the distance to DHO38, while the maximum number of single pulses in each measurement (black) is mostly constant and often coincides with the transmitting frequency of DHO38. (B) Device settings of the Cerescope for the measurements displayed in (A).

Fig. 4c). In this respect, the French VLF transmitter HWU (distance to measuring location $827 \mathrm{~km}$; bearing $235^{\circ}$ ) represents a possible source of the signals shown in Fig. 4c. This is supported by measurements carried out close to Frankfurt am Main (Germany) with high amplifications showing a plateau at 1830 single pulses per $100 \mathrm{~ms}$, coinciding with the transmission frequency of HWU at $18.3 \mathrm{kHz}$, and minimum intensities in a direction coinciding with its bearing (Fig. 8). The source of the measured direction in Fig. $7 \mathrm{c}$ seems to be the discontinuous signal of the Russian VLF transmitter RDL Krasnodar. This transmitter caused the most intensive signal in Northern Germany during the intermission of DHO38 on 15 July 2009, corresponding to the Kiel Longwave Monitor (www.df3lp.de).

We therefore propose that an influence of the daily intermission of the broadcasting of DHO38 on Cerescope measurements is proven. Moreover, the fluctuations of EMR intensities and main $B_{\mathrm{EMR}}$ directions measured during the turn of the year (Fig. 4) can be explained by the annual transmis- sion pattern of DHO38 (Fig. 6b). It shows a regular intermission at the turn of the year, when the transmitter is commonly turned off for several days (cf. SID Monitoring Station: http://sidstation.loudet.org/home-en.xhtml). The beginning and the end of this intermission coincide exactly with the timing of the observed fluctuations of the main $B_{\mathrm{EMR}}$ directions as described above (Sect. 3.2). Furthermore, the simultaneous fluctuations in intensities can be explained by a turn off of the steady signal from DHO38.

\section{Technical problems that limit the applicability of the EMR method}

According to our results, Cerescope measurements are strongly influenced by artificial signals from VLF transmitters. Even though all Cerescope measurements described above were carried out with band-pass filters that omit the transmission frequencies of DHO38 $(23.4 \mathrm{kHz})$ and HWU $(18.3 \mathrm{kHz})$, the observations indicate that this filter does not 

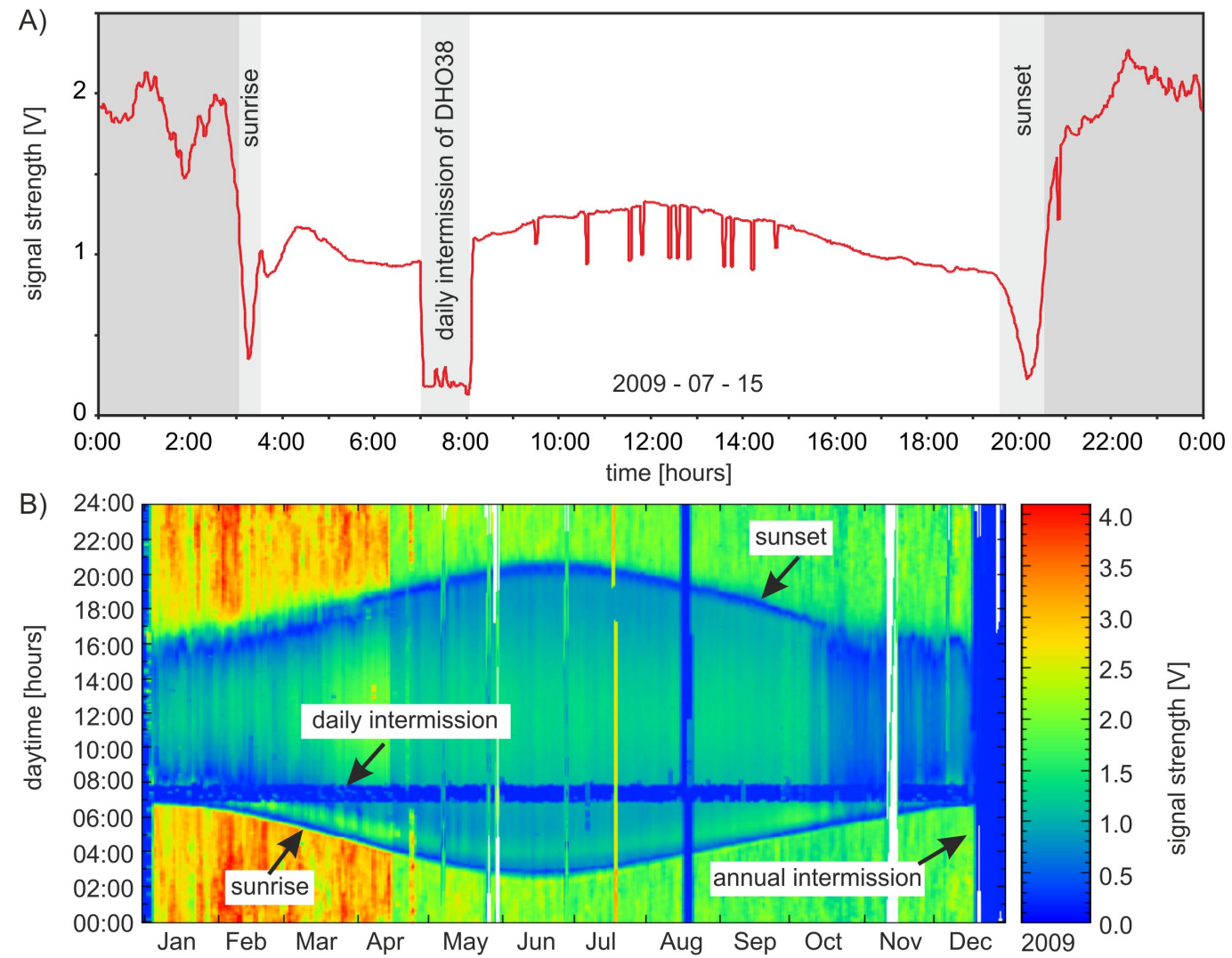

Fig. 6. Signal-strength variation of DHO38, modified after SID Monitoring Station: http://sidstation.loudet.org/home-en.xhtml. (A) Daily broadcasting pattern as received near Toulouse on 15 July 2009. Between sunrise and sunset the received signal strength is nearly constant. During night, sunrise, and sunset the received signal strength varies over a wide range. Between 07:00 and 08:00 UTC a regular daily intermission in the broadcasting of DHO38 is abided. This daily intermission occurs throughout the year. (B) Annual broadcasting pattern. A seasonal influence is related to the solar altitude. An intermission in the broadcasting during several days is scheduled during the turn of every year.

work effectively. To test its functionality, three horizontal measurements were carried out near Göttingen over three different frequency ranges $(5-10 \mathrm{kHz}, 20-30 \mathrm{kHz}, 30-35 \mathrm{kHz})$ within a short time interval of $15 \mathrm{~min}$. The results show maximum intensities in the direction of $45^{\circ} \pm 10^{\circ}$, i.e. perpendicular to the direction towards DHO38, independent of the evaluated frequency range (Fig. 9). Consequently, the signal strength of the defining energy is highest in the range between 20 to $30 \mathrm{kHz}$, which encloses the transmitting frequency of DHO38. However, the higher intensities measured at higher frequencies $(30-35 \mathrm{kHz})$ compared to the intensities of the lower frequencies $(5-10 \mathrm{kHz})$ contradict the skin depth of electromagnetic waves that increases with lower frequencies and should thus result in higher intensities at lower frequencies (see Sect. 2). Furthermore, a second peak appears in the measured defining energy in the 5 to $10 \mathrm{kHz}$ range (Fig. 9b). This second peak or anomaly occurs in a direction of about $175^{\circ}$ and coincides with the direction measured during the daily intermission of DHO38 (Fig. 7c), which is possibly related to signals from the Russian VLF transmitter RDL Krasnodar. This demonstrates the insufficiency of the band-pass filter caused by its flat frequency response and the failure of the filter system to remove artificial signals based on their intransient character.

Further measurements were carried out to test the applicability of the other available filter types. The high- and lowpass filters possess the same flat frequency response as the band-pass filters and are therefore non-effective. The notch filters, in contrast, are able to eliminate even the strong signal of DHO38. If using one notch filter to remove the strongest signal visible on the spectrum display of the Cerescope, the orientation of the main $B_{\mathrm{EMR}}$ direction changes to the direction towards the next strongest VLF transmitter receivable at the measuring point (Fig. 10). Accordingly, the notch filters (1) have a steep enough frequency response, (2) are broad enough to remove the signals even if they are not purely monochromatic, and (3) are on the other hand narrow enough to let signals at other frequencies pass. However, the problem becomes obvious by examining data received with the Cerescope antenna during a horizontal measurement with 
A)

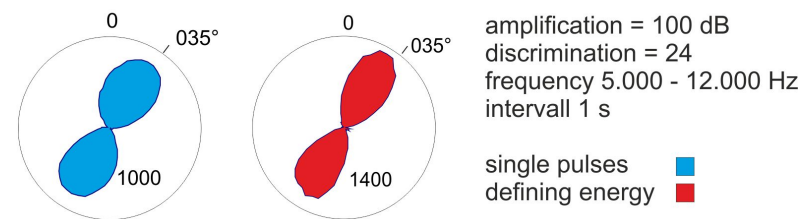

B)
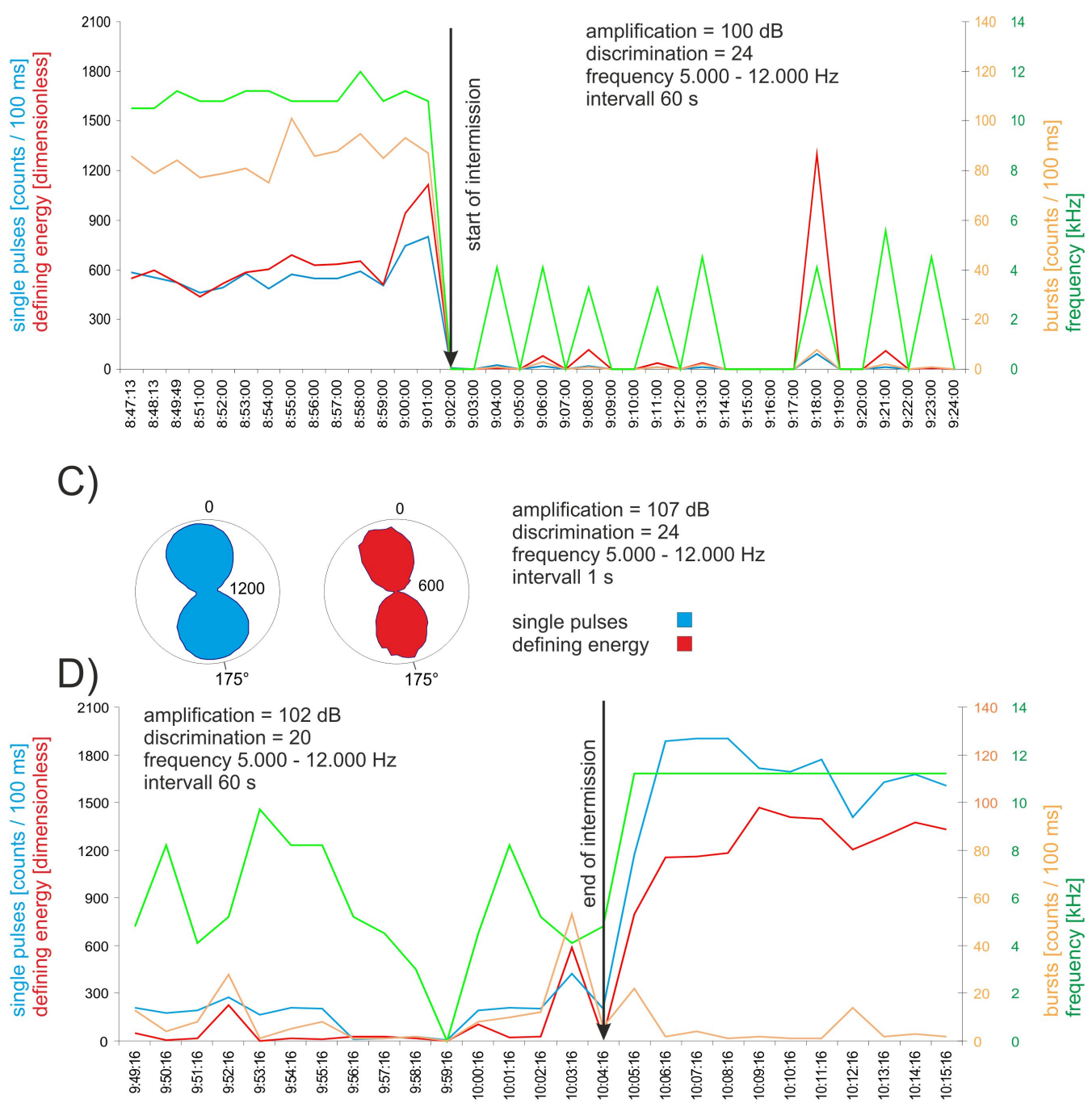

Fig. 7. Results of Cerescope measurements on 15 July 2009 near Göttingen (Germany) showing the effects of the daily intermission in the regular broadcasting of DHO38. (A) Horizontal measurement results before the intermission. (B) Time-triggered measurement during the turn off of DHO38 with the antenna oriented horizontally pointing towards $45^{\circ}$. (C) Results of a horizontal measurement during the intermission. (D) Time-triggered measurement during the turn on of DHO38 with the antenna oriented horizontally pointing towards $45^{\circ}$.

$5^{\circ}$ increments $30 \mathrm{~km} \mathrm{NW}$ of Frankfurt am Main (Germany). These signals were recorded for $0.2 \mathrm{~s}$ at each increment by the analogue to digital converter AK 5385 implemented in the USB-Interface EMU 0204, which has a sampling rate of $192 \mathrm{kHz}$, a resolution of $24 \mathrm{bit}$, and an infinitely variable low-noise pre-amplifier. The resulting normalised logarith- mic spectrogram calculated from the power spectra of each increment allows identification of eight VLF transmitters by their specific frequency and their orientation in the frequency range between 15 and $25 \mathrm{kHz}$ alone (Figs. 11, 12). Thus, the two available notch filters should in practise be insufficient to remove all artificial signals over the complete frequency 


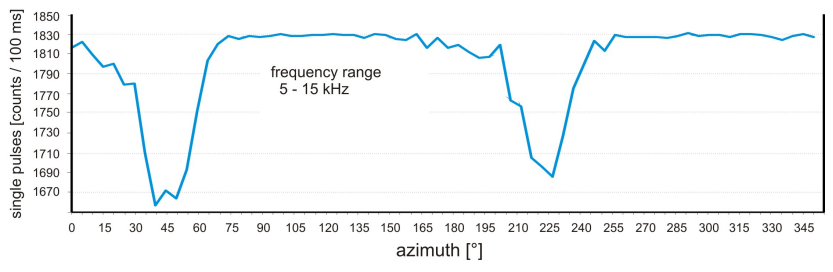

Fig. 8. Results of a horizontal measurement recorded close to Frankfurt am Main (Germany) with a higher amplification (117 dB), a discrimination of 24 and a band-pass filter between 5 and $15 \mathrm{kHz}$ on 19 December 2011 during the annual intermission of DHO38. The plateau at 1830 single pulses per $100 \mathrm{~ms}$ and the direction of the minimum intensities point to the French VLF transmitter HWU broadcasting at $18.3 \mathrm{kHz}$.

range between 5 and $50 \mathrm{kHz}$ used by the Cerescope. In addition, the flat frequency response of the band-, low- and high-pass filters does not allow the selection of a narrow frequency range that excludes signals from VLF transmitters (cf. Fig. 9).

As indicated by the circular pattern of the main $B_{\mathrm{EMR}}$ directions surrounding DHO38, the receiving pattern of the Cerescope antenna is not unidirectional, with the highest sensitivity for a propagation direction of the electromagnetic field parallel to its long axis, as stated by Lichtenberger (2005, 2006a), and Reuther and Moser (2009). The Cerescope antenna has a ferrite core. Such antennas are only sensitive to the magnetic component of electromagnetic fields, and their maximum sensitivity is achieved when the antenna is oriented with its long axis parallel to the magnetic flux lines, i.e. perpendicular to their propagation direction (e.g. Bergmann et al., 1999). This is also evident for the signals from the stronger, or closer, VLF transmitters (Fig. 12), where the minimum spectral power coincides with the direction towards the VLF transmitters. Furthermore, we believe line measurements (see Sect. 2) that are used to detect active faults should be attributed to the VLF method (e.g. Bastani, 2001; Persson, 2001; Persson et al., 2011). Here, the antenna is typically held in a vertical position and thus is insensitive towards the horizontally propagating primary VLF fields; vice versa it becomes sensitive to the vertical oriented component of the secondary magnetic VLF field that is induced within structures of higher electric conductivity like fault zones (for more details see Krumbholz, 2010a; Krumbholz et al., 2011). This may explain the higher intensities measured at some localities (marked by blue squares in Fig. 5).

\section{Implications for previous studies}

As demonstrated by systematic investigations covering a large area and a long time span, the natural component of EMR cannot be detected with the Cerescope at unshielded locations at the Earth's surface due to its sensitivity to arti-
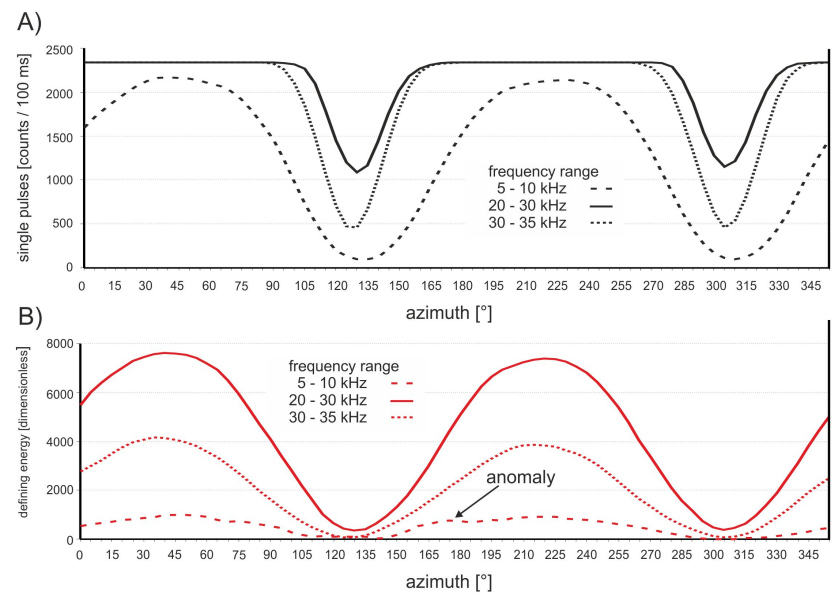

Fig. 9. Comparison of three horizontal measurements using different frequency ranges but otherwise the same device settings: amplification $107 \mathrm{~dB}$ and discrimination level of 24. (A) Intensities of single pulses and (B) defining energy vs. the azimuth (long axis of antenna with regard to north $=0^{\circ}$ ). The small anomaly coincides with direction measured during the broadcasting intermission of DHO38 on 15 July 2009 and is probably related to RDL Krasnodar in Russia.

ficial sources, such as VLF transmitters. Consequently, the measured signals are not related to crack-induced emissions, and hence they are unusable for the determination of crustal stress directions. Therefore, results of previous studies that used the Cerescope and interpreted the $B_{\mathrm{EMR}}$ data in geological terms need to be re-evaluated.

The most obvious of our observations, the daily intermission of DHO38 between 07:00 and 08:00 UTC, can be also found in data sets of Lauterbach (2005) and Greiling and Obermeyer (2010a). Lauterbach (2005) attributed his $B_{\mathrm{EMR}}$ patterns to the interactions of the diurnal cycle of the terrestrial magnetic field and ionospheric effects. Greiling and Obermeyer (2010a) interpreted the signal development in time as a combination of the diurnal cycle of the terrestrial magnetic field, Earth tides, and astronomic influences. Both studies, however, give no satisfying explanation for the behaviour over time.

The influence of different VLF transmitters is also evident from horizontal measurements by Lichtenberger (2006a), who observed repeated changes between different main $B_{\text {EMR }}$ directions at the same location at different times. He explained this by the episodic activation of different fracture systems or parts of conjugate fracture systems and assumed $\sigma_{H}$ to be along the bisectrix of the most often observed $B_{\mathrm{EMR}}$ directions. This approach is questionable as micro-cracks in the uppermost crust commonly form as Mode I cracks, parallel to $\sigma_{H}$ (e.g. Kranz, 1983; Vollbrecht et al., 1989, 1999; Zang et al., 1996). Additionally, micro-cracks belonging to a conjugate system should by definition be active at the same time and enclose only a small angle of up to $60^{\circ}$ which is not 


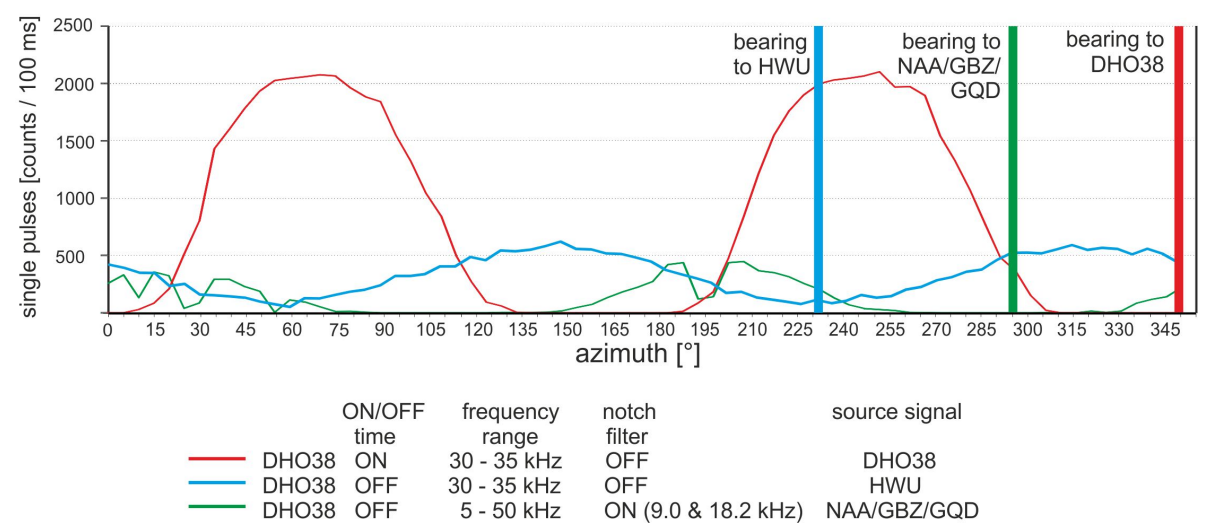

Fig. 10. Validation of the effects of DHO38 intermissions and notch filters. Measurements were carried out close to Frankfurt am Main (Germany). Band-pass filters applied before (red line) and during (blue line) the intermission of DHO38 produce measurement results pointing towards DHO38 and HWU, respectively. Applying a notch filter during the intermission of DHO38 at $18.2 \mathrm{kHz}$ and $9 \mathrm{kHz}$ causes a switch of the main $B_{\text {EMR }}$ towards other VLF transmitters. NAA (USA), GBZ (United Kingdom) and GQD (United Kingdom) represent possible sources.

in agreement with the main $B_{\mathrm{EMR}}$ directions and their occasional appearance as observed by Lichtenberger (2006a). Moreover, the considered crack systems are only hypothetical, i.e. not directly observed. Alternatively, the main $B_{\mathrm{EMR}}$ directions by Lichtenberger (2006a) can easily be related to the locations of different VLF transmitters (for example DHO38 and HWU) (Krumbholz, 2010a, b).

On the Hyblean Plateau (SE Sicily), Reuther et al. (2002) repeatedly measured two different main $B_{\mathrm{EMR}}$ directions over several tens of kilometres (C. D. Reuther, personal communication, 2012) that correlate well with local stress data obtained by conventional methods (WSM, Heidbach et al., 2008). However, both directions could also be well explained by signals from the VLF transmitters DHO38 and RDL Krasnodar, measured at different times of the day (depending on broadcasting times or signal strengths as a function of the altitude of the Sun) or with different frequency ranges. Since Reuther et al. (2002) do not give all relevant details of their measurements, a final decision about the source of their signals cannot be made.

Further studies by Lauterbach (2005) and Mallik et al. (2008) show results that strongly deviate from stress directions given in the WSM (Heidbach et al., 2008; see Krumbholz, 2010a for the maps), but can easily be explained by the signals of VLF transmitters. These facts have previously been discussed by Krumbholz (2010b) and Greiling and Obermeyer (2010b), particularly regarding the results of Mallik et al. (2008) that show a misfit of about $60^{\circ}$ to the WSM data as well as a significant deviation from the sub-recent stress field, obtained directly from the orientation of sub-recent structural features like folds and faults. VLF transmitters that might explain Lauterbach's (2005) measurements are DHO38 and HWU, while measurements of Mallik et al. (2008) might be affected by VTX $\left(19.2 \mathrm{kHz} ; 8^{\circ} 23^{\prime} \mathrm{N}\right.$, $\left.77^{\circ} 45^{\prime} \mathrm{E}\right)$.
For an evaluation of the influence of VLF transmitters on the horizontal EMR measurements by Reuther and Moser (2009) in Patagonia (South America), information about the location and broadcasting of VLF transmitters in this area is not present. The deduced $\sigma_{H}$ directions agree with the WSM over large areas; however, several circular patterns as described in Sects. 3 and 4 and shown in Fig. 3 also occur.

Furthermore, our observation of a maximum number of counts per $100 \mathrm{~ms}$, which is expressed in a plateau-shaped maximum (Figs. 8, 9) and can be explained by the broadcasting frequency of the respective VLF transmitter, is also documented in the results of Greiling and Obermeyer (2010a).

Lichtenberger (2005, 2006a, b) also performed vertical EMR measurements in tunnels to determine stress concentrations, as well as to determine stress directions and magnitudes. He assumed that the EMR signals measured at depths of up to $180 \mathrm{~m}$ were unaffected by VLF transmitters because of the damping by the overburden. This assumption, however, contradicts other studies (e.g. Takahara et al., 2010) which show that the skin depth of EMR can easily reach hundreds of meters in different rock types. Furthermore, the results of these studies are highly questionable because of his wrong assumptions regarding the interpretation of the receiving pattern of the antenna (cf. Sect. 2 and Sect. 5).

Additionally, Lichtenberger (2005, 2006a, b) describes that, in general, the measured intensities increased towards the tunnel entrances. The same effect was observed in boreholes by Lauterbach (2005), who described decreasing EMR intensities with depth. Considering the above defined skin depth of EMR, these observations have to be related to artificial sources at the surface. 


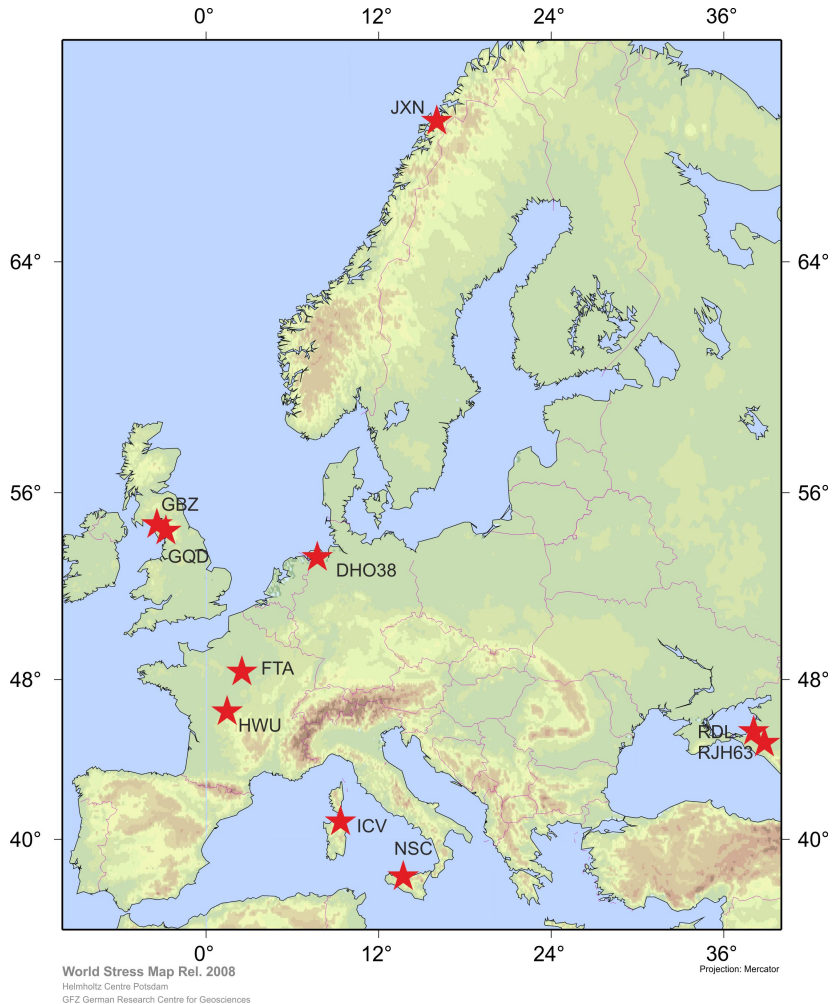

Fig. 11. Positions of some of the most intensive European VLF transmitters (cf. Fig. 12): JXN $\left(16.4 \mathrm{kHz} ; 66^{\circ} 58^{\prime} \mathrm{N}, 13^{\circ} 52^{\prime} \mathrm{E}\right.$; Norway), GBZ (19.6 kHz; 54ํำ $54^{\prime} \mathrm{N}, 3^{\circ} 16^{\prime} \mathrm{W}$; United Kingdom), GQD $\left(22.1 \mathrm{kHz} ; 54^{\circ} 43^{\prime} \mathrm{N}, 2^{\circ} 53^{\prime} \mathrm{W}\right.$; United Kingdom), DHO38 $\left(23.4 \mathrm{kHz} ; 53^{\circ} 4^{\prime} \mathrm{N}, 7^{\circ} 36^{\prime} \mathrm{E}\right.$; Germany), FTA $\left(20.9 \mathrm{kHz} ; 48^{\circ} 32^{\prime} \mathrm{N}\right.$, $2^{\circ} 34^{\prime} \mathrm{E}$; France), HWU (18.3 kHz; $46^{\circ} 42^{\prime} \mathrm{N}, 1^{\circ} 14^{\prime} \mathrm{E}$; France), ICV $\left(20.27 \mathrm{kHz} ; 40^{\circ} 55^{\prime} \mathrm{N}, 9^{\circ} 43^{\prime} \mathrm{E}\right.$; Italy), NSC $\left(45.9 \mathrm{kHz} ; 37^{\circ} 00^{\prime} \mathrm{N}\right.$, $13^{\circ} 30^{\prime} \mathrm{E}$; Italy), RJH63 (25.0, 25.1, 25.5, 23.0 and $20.5 \mathrm{kHz}$; $44^{\circ} 46^{\prime} \mathrm{N}$, $39^{\circ} 34^{\prime} \mathrm{E}$; Russia), and RDL Krasnodar $(18.1 \mathrm{kHz}$; $45^{\circ} 24^{\prime} \mathrm{N}, 38^{\circ} 09^{\prime} \mathrm{E}$; Russia). (Map modified after Heidbach et al., 2008.)

\section{Conclusions}

Based on repeated $B_{\mathrm{EMR}}$ measurements with two Cerescopes over an area of about $250000 \mathrm{~km}^{2}$ and over a time span of $1.5 \mathrm{yr}$, we conclude that the EMR method using the Cerescope is currently not applicable to determine the $\sigma_{H}$ direction. There is strong evidence that EMR signals detected with the Cerescope are not related to geological sources but instead are controlled by VLF transmitters. The same holds for the detection of active faults using line measurements; this should be attributed to the common VLF method and is not based on the registration of an increased number of micro-cracks in the vicinity of fault zones.

The most significant results leading to this conclusion can be summarised as follows: The main $B_{\mathrm{EMR}}$ directions form a circular pattern around a known VLF transmitter (DHO38 in north-west Germany). The received signal strength of the defining energy is a function of the distance to $\mathrm{DHO} 38$, while

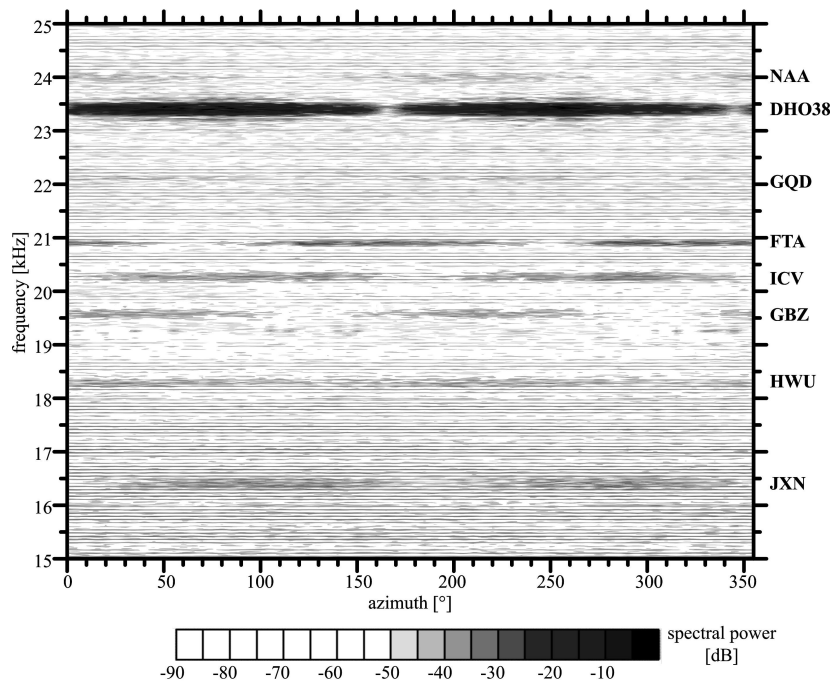

Fig. 12. Normalised logarithmic spectrogram calculated from the power spectra of each azimuthal $5^{\circ}$ increment of the magnetic field measured by the Cerescope antenna that was connected to a separate analogue to digital converter. Signals of eight VLF transmitters can be identified by their frequency. Their bearing with respect to the investigation area next to Frankfurt am Main (Germany) are shown by the minimum of the spectral power (cf. Fig. 11): JXN $\left(16.4 \mathrm{kHz}\right.$; distance to measuring location $1892 \mathrm{~km}$; bearing $007^{\circ}$ ), GBZ $(19.6 \mathrm{kHz}$; distance to measuring location $942 \mathrm{~km}$; bearing $\left.308^{\circ}\right)$, GQD $(22.1 \mathrm{kHz}$; distance to measuring location $910 \mathrm{~km}$; bearing $\left.308^{\circ}\right)$, DHO38 $(23.4 \mathrm{kHz}$; distance to measuring location $322 \mathrm{~km}$; bearing $\left.352^{\circ}\right)$, FTA $(20.9 \mathrm{kHz}$; distance to measuring location $456 \mathrm{~km}$; bearing $\left.248^{\circ}\right)$, HWU $(18.3 \mathrm{kHz}$; distance to measuring location $652 \mathrm{~km}$; bearing $\left.236^{\circ}\right)$, ICV $(20.27 \mathrm{kHz}$; distance to measuring location $1039 \mathrm{~km}$; bearing $\left.173^{\circ}\right)$, NAA $(24.0 \mathrm{kHz}$; distance to measuring location $5488 \mathrm{~km}$; bearing $294^{\circ} ; 44^{\circ} 38^{\prime} \mathrm{N}, 67^{\circ} 16^{\prime} \mathrm{W}$; USA).

the observed maximum number of measured single pulses per unit time correlates with the transmission frequency of DHO38. Variations in signal strength and main $B_{\mathrm{EMR}}$ direction correlate directly with the broadcasting time of DHO38, and, in addition, reflect the typical daily variations for the reception of VLF signals dependent on the altitude of the Sun.

Concerning the design of the applied Cerescope, the evident problems are:

1. The band-, high-, and low-pass filters are not able to filter the artificial frequencies effectively because of their flat response function.

2. The notch filters seem to be effective, but only two can be used at the same time. Consequently, due to the density of VLF transmitters in combination with their high range of coverage and the in some cases irregular broadcasting times, they are not sufficient to remove all VLF signals. 
3. The burst detection algorithm that should reject artificial signals by analysing the shape of the signals does not work effectively enough.

Furthermore, the operating mode of the Cerescope according to the internal signal processing is unknown, because neither the raw data nor a detailed description of the processing algorithm is available. In addition, some previous studies describe the receiving pattern of the antenna as most sensitive if its long axis is parallel to the propagation direction of the electromagnetic field. However, the antenna, like all ferrite-core antennas, has its maximum sensitivity for magnetic fields parallel to its long axis and perpendicular to their propagation direction.

In summary, this study demonstrates that $B_{\mathrm{EMR}}$ measurements with the Cerescope at its current state of development are not applicable for determining the orientation of $\sigma_{H}$, because the measured signals are dominated by artificial sources that overprint any potentially micro-crack related signal. Therefore, previous studies which have applied the here discussed EMR method and have interpreted the detected signals in geological terms should be critically reviewed.

Since the principles of the method based on laboratory studies (e.g. Koktavy et al. (2004); Misra and Kumar, 2004) are convincing, future work with the aim to use crack-related EMR as a tool to study crustal stresses would be desirable. Hence, further methodological development has to solve the problem to identify and measure micro-crack induced $B_{\mathrm{EMR}}$ and its directional properties under unshielded field conditions. For this purpose, a measurement device that provides high-quality raw data would also require three synchronized and continuously recording receivers to allow a determination of the stress tensor. Based on these data, new algorithms have to be developed to remove artificial signals and to identify specific signal shapes of crack-related electromagnetic waves. In addition, atmospheric and lithospheric signals have to be distinguished (e.g. Nikiforova et al., 1989), for which further research and development is needed.

Acknowledgements. We thank our colleagues from Göttingen, Mainz, and Uppsala for their help and critical discussions, with special thanks to Bernd Leiss, Jens Walter, Bent Hansen, Sharon Webb, Klaus Wemmer, David C. Tanner, and Laust Pedersen. We also thank Mark Everett, Daniel Köhn, the two anonymous reviewers and Charlotte Krawczyk for providing a fair and unbiased review process, and for their comments that helped to improve the quality of our manuscript.

This Open Access Publication is funded by the University of Göttingen.

Edited by: C. Krawczyk

\section{References}

Bahat, D., Frid, V., Rabinovitch, A., and Palchik, V.: Exploration via electromagnetic radiation and fractographic methods of fracture properties induced by compression in glass-ceramic, Int. J. Fracture, 116, 179-194, 2002.

Bastani, M.: EnviroMT - A new controlled source/radio magnetotelluric system, Ph.D. thesis, University of Uppsala, Sweden, 179 pp., 2001.

Bergmann, L., Schäfer, C., and Raith, W.: Lehrbuch der Experimentalphysik, Bd. 2: Elektromagnetismus, Gruyter, Berlin, Germany, 1999.

Brady, B. T. and Rowell, G. A.: Laboratory investigation of the electrodynamics of rock fracture, Nature, 321, 488-492, 1986.

Clint, O. C.: Electrical potential changes and acoustic emissions generated by fracture and fluid flow during experimental triaxial rock deformation, Ph.D. thesis, University of London, London, UK, 236 pp., 1999.

Derr, J. S.: Luminous phenomena and their relationship to rock fracture, Nature, 321, 470-471, 1986.

Enomoto, Y. and Hashimoto, H.: Emission of charged particles from indentation fracture of rock, Nature, 346, 641-643, 1990.

Enomoto, Y. and Hashimoto, H.: Transient electrical activity accompanying rock under indentation loading, Tectonophysics, 211, 337-344, 1992.

Fifolt, D. A., Petrenko, V. F., and Schulson, E. M.: Preliminary study of electromagnetic emissions from cracks in ice, Philos. Mag. B., 67, 289-299, 1993.

Frid, V., Rabinovitch, A., and Bahat, D.: Fracture induced electromagnetic radiation, J. Phys. D Appl. Phys., 36, 1620-1628, 2003.

Gershenzon, N. and Bambakidis, G.: Modeling of seismoelectromagnetic phenomena, Russ. J. Earth Sci., 3, 247-275, 2001.

Gershenzon, N. and Gokhberg, M.: On the origin of electrotelluric disturbances prior to an earthquake in Kalamata, Greece, Tectonophysics, 224, 169-174, 1993.

Ghomshei, M. M. and Templeton, T. L.: Piezoelectric and a-axes fabric along a quartz vein, Phys. Earth Planet Int., 55, 374-386, 1989.

Greiling, R. O. and Obermeyer, H.: Natural electromagnetic radiation (EMR) and its application in structural geology and neotectonics, J. Geol. Soc. India, 75, 278-288, 2010a.

Greiling, R. O. and Obermeyer, H.: Discussion: Natural electromagnetic radiation (EMR) and its application in structural geology and neotectonics, J. Geol. Soc. India, 76, 289-290, 2010 b.

Heidbach, O., Tingay, M., Barth, A., Reinecker, J., Kurfeß, D., and Müller, B.: The World Stress Map database release 2008, doi:10.1594/GFZ.WSM.Rel2008, 2008.

Kiel Longwave Monitor: http://www.df3lp.de/, last access: 5 March 2012.

King, C. Y.: Electromagnetic emissions before earthquakes, Nature, 303, 377, 1983.

Koktavy, P., Pavelka, J., and Sikula, J.: Characterization of acoustic and electromagnetic emission sources, Meas. Sci. Technol., 15, 973-977, 2004.

Kranz, R. L.: Microcracks in rocks: a review, Tectonophysics, 100, 449-480, 1983.

Krumbholz, M.: Electromagnetic radiation as a tool to determine actual crustal stresses - applications and limitations, Ph.D. thesis, University of Göttingen, Germany, 151 pp., 2010a. 
Krumbholz, M.: Discussion: natural electromagnetic radiation (EMR) and its application in structural geology and neotectonics by R. O. Greiling and H. Obermeyer, J. Geol. Soc. India, 76, 289-290, 2010b.

Krumbholz, M., Vollbrecht, A., Leiss, B., Grossmann, J., and Hachmeister, H.: Lokalisierung von Störungen im Bereich der Leinetalgrabenstruktur mittels VLF-Methode: Diskussion erster Ergebnisse, in: GGG: Neuere Untersuchungen zur Geologie der Leinetalgrabenstruktur - Bausteine zur Erkundung des geothermischen Nutzungspotentials in der Region Göttingen, edited by: Leiss, B., Tanner, D., Vollbrecht, A., Universitätsverlag Göttingen, Germany, 107-113, 2011.

Lauterbach, M.: Beurteilung der Eignung der NPEMFE-Methode (Natural Pulsed Electromagnetic Field of Earth) mit dem "Cereskop" in Rutschungen und in Locker- und Festgesteinen mit Spannungsänderungen im Mittel- und Hochgebirge, Ph.D. thesis, University of Mainz, Germany, 243 pp., 2005.

Lichtenberger, M.: Regional stress field as determined from electromagnetic radiation in a tunnel, J. Struct. Geol., 27, 2150-2158, 2005.

Lichtenberger, M.: Bestimmen von Spannungen in der Lithosphäre aus geogener elektromagnetischer Strahlung, Ph.D. thesis, University of Heidelberg, Germany, 140 pp., 2006a.

Lichtenberger, M.: Underground measurements of electromagnetic radiation related to stress-induced fractures in the Odenwald Mountains (Germany), Pure Appl. Geophys., 163, 1661-1677, 2006b.

Mallik, J., Mathew, G., Angerer, T., and Greiling, R. O.: Determination of directions of horizontal principal stress and identification of active faults in Kachchh (India) by electromagnetic radiation (EMR), J. Geodyn., 45, 234-245, 2008.

Misra, A.: Electromagnetic effects at metallic fracture, Nature, 254, 133-134, 1975.

Misra, A. and Gosh, S.: Electromagnetic radiation characteristics during fatigue crack propagation and failure, Appl. Phys., 23, 387-390, 1980 .

Misra, A. and Kumar, A.: Some basics of electromagnetic radiation during crack propagation in metals, Int. J. Fracture, 127, 387401, 2004.

Mori, Y. and Obata, Y.: Electromagnetic emission and AE Kaiser effect for estimating rock in-situ stress, Report of the Research Institute of Industrial Technology, Nihon University, 2008

Nagamoto, H., Fukushima, T., Ida, Y., Matsudo, Y., and Hayakawa, M.: Disturbances in VHF/UHF telemetry links as a possible effect of the 2003 Hokkaido Tokachi-oki earthquake, Nat. Hazards Earth Syst. Sci., 8, 813-817, doi:10.5194/nhess-8-813-2008, 2008.

Nikiforova, N. N., Yudakhin, F. N., and Toktospiev, A. M.: Studies of electromagnetic emissions of seismotectonic origin in the Kirghiz SSR, Phys. Earth Planet. In., 57, 68-75, 1989.

Nitsan, V.: Electromagnetic emission accompanying fracture of quartz-bearing rocks, Geophys. Res. Lett., 4, 333-336, 1977.

Obermeyer, H.: Measurement of natural pulsed electromagnetic radiation (EMR) with the Cerescope, Unpublished manual, Ceres $\mathrm{GmbH}$, Staffort, Germany, 2005a.

Obermeyer, H.: Handbuch zur Anwendung der NPEMFE-Methode mittels des Cereskops, Unpublished manual, Ceres $\mathrm{GmbH}$, Staffort, Germany, 2005b.
O'Keefe, S. O. and Thiel, D. V.: A mechanism for the production of electromagnetic radiation during fracture of brittle materials, Phys. Earth Planet. In., 89, 127-135, 1995.

Parkhomenko, E. S.: Electrification Phenomena in Rocks, Plenum Press, New York, UK, 1971.

Persson, L.: Plane wave electromagnetic measurements for imaging fracture zones, Ph.D. thesis, University of Uppsala, Sweden, 132 pp., 2001.

Persson, L., Lundin, I. A., Pedersen, L. B., and Claeson, D.: Combined magnetic, electromagnetic and resistivity study over a highly conductive formation in Orrivaara, Northern Sweden, Geophys. Prospec., 59, 1155-1163, doi:10.1111/j.13652478.2011.00998.x, 2011.

Petrenko, V. F.: On the nature of electrical polarization of materials caused by cracks - application to ice electromagnetic emission, Philos. Mag. B, 67, 301-315, 1993.

Rabinovitch, A., Frid, V., and Bahat, D.: Surface oscillations a possible source of fracture induced electromagnetic radiation, Tectonophysics, 431, 15-21, 2007.

Reuther, C. and Moser, E.: Orientation and nature of active crustal stresses determined by electromagnetic measurements in the Patagonian segment of the South America Plate, Int. J. Earth Sci., 98, 585-599, 2009.

Reuther, C., Obermeyer, H., Reicherter, K., Reiss, S., Kaiser, A., Buchmann, T., Adam, J., Lohrmann, J., and Grasso, M.: Neotektonik und aktive Krustenspannung in Südost-Sizilien und ihre Beziehung zur regionalen Tektonik im Zentralen Mittelmeer, Mitteilungen Geologisches Paläontologisches Institut, University of Hamburg, Germany, 86, 1-24, 2002.

SID Monitoring Station: http://sidstation.loudet.org/home-en. xhtml, last access: 5 March 2012.

Slifkin, L.: Seismic electric signals from displacement of charged dislocations, Tectonophysics, 224, 149-152, 1993.

Takahara, K., Muto, J., and Nagahama, H.: Skin depth of electromagnetic wave through fractal crustal rocks, IEEJ T. Fund. Mater., 130, 258-264, 2010.

Vollbrecht, A., Rust, S., and Weber, K.: Mikrorißgenerationen in der KTB-Vorbohrung und im Umfeld, KTB-Report, 89, 111-119, 1989.

Vollbrecht, A., Stipp, M., and Olesen, N. Ø.: Crystallographic orientation of microcracks in quartz and inferred deformation processes: a study on gneisses from the German Continental Deep Drilling Project (KTB), Tectonophysics, 303, 279-297, 1999.

Yamada, I., Masuda, K., and Mizutani, H.: Electromagnetic emission associated with rock fracture, Phys. Earth Planet. Int., 57, 157-168, 1989.

Yoshida, S. and Ogawa, T.: Electromagnetic emissions from dry and wet granite associated with acoustic emissions, J. Geophys. Res., 109, B09204, doi:10.1029/2004JB003092, 2004.

Zang, A., Lienert, M., Zinke, J., and Berckhemer, H.: Residual strain, wave speed and crack analysis of crystalline cores from the KTB-VB well, Tectonophysics, 263, 219-234, 1996. 